\title{
Direct Torque Control of Induction Motor with Cascaded Multilevel inverter
}

\author{
B. Kiran Kumar ${ }^{1}$, Dr. Y.V. Siva Reddy ${ }^{2}$ and Dr. M. Vijaya Kumar ${ }^{3}$ \\ Research Scholar, Dept. of EEE, JNTUA College of Engineering, Anantapur ${ }^{1}$ \\ Professor, Dept. of EEE, G.Pullareddy Engineering College, Kurnool ${ }^{2}$ \\ Professor, Dept. of EEE, JNTUA College of Engineering, Anantapur ${ }^{3}$
}

\begin{abstract}
In this Paper, an Intelligent Direct Torque Control (DTC) method is proposed for controlling induction motor using Multilevel inverter with space Vector Modulation (SVM).A stage of Artificial Neural Network (ANN) is utilised for predicting the target parameters with the corresponding input parameters change in motor torque and flux. The change in motor torque and flux parameters are extracted from the behaviour of the system with PI controller. The back propagation learning method is used to learn the ANN. By using the ANN output and PI controller outputs, PWM control signal are generated from the SVM technique and control the multilevel inverter. Then the proposed intelligent control technique is implemented in the MATLAB/Simulink and the effectiveness are analysed with five level cascaded inverter and comparing the results with PI controller and the proposed case. The comparison results shows that the proposed method have good speed control response.
\end{abstract}

Keyword: DTC, SVM, ANN, Multilevel inverter, Induction motor.

\section{INTRODUCTION}

In Industrial, commercial and domestic applications, Induction Motors (IMs) are commonly used because they are simple, Shaggy, economic in cost and easy to maintain [1]. The constant speed drives are used in most of the induction machines [2]. Whenever the load is fluctuates Induction motor is complex to sustain a constant speed [3]. The beginning of new semiconductor devices has made variable speed drives with induction machines accessible during the last decades [4]. The high performance electric speed drives needs decoupled torque and flux control [5]. This method is generally afforded through Field oriented control (FOC) or vector control method [6]. The excitation current and load current can be controlled individually by using FOC method. Hence, flux and torque also be separately controlled correspondingly in DC motor [7]. To control pulse-width-modulation in the inverter system, the FOC method needs current controller, coordinate transformation and current regulator [8]. But FOC needs efficient and complex calculation of the decoupling, so it is complex to perform and in high performance electric speed drive an easily towards by load disturbance and parameter uncertainties [9].

The usual direct torque control (DTC) switching table failed to consider the circuit limitations, like neutral-pointbalance and smooth vector switching, basis by the topology of a three-level inverter. Two types of adapted schemes for three-level DTC were presented to solve these problems. Fuzzy logic control and the speed-adaptive flux observer were introduced to develop their performance of the system. The concern of large starting current was explored and solved by introducing the method of pre excitation [10]. The fuzzy logic controller (FLC) was used to vary the bandwidth of the torque hysteresis controller so as to decrease the torque and flux ripples and, hence, to enhance the motor dynamic response.
The effects of torque hysteresis bandwidth on the amplitude of torque ripples of an IM were also illustrated. Based on the slopes of motor-estimated torque and stator current, an FLC was constructed to choose the possible bandwidth of the torque hysteresis controller [11]. The design methodology was based on space vector modulation (SVM) of Induction machine with direct torque control (DTC), with the PI controller in the torque control loop has been replaced with the Artificial neural network(ANN) which works based on the training and testing process. This network is trained by back propagation training algorithm. The back propagation algorithm is one of the most famous algorithms to train a feed forward network

\section{PROPOSED CONTROL METHOD}

In the proposed adaptive technique, the speed control parameters will be estimated by artificial intelligence. Subsequently, the estimated optimal parameters based PWM control signal will be generated, which will be then applied to the gate of the multilevel inverters. In the proposed control scheme, the speed variation of the motor will be measured from the rotor shaft position. For the reason that the rotor shaft position will ensure the speed range behaviour of the motor. The design methodology was based on space vector modulation (SVM) of Induction machine with direct torque control (DTC), with the PI controller in the torque control loop has been replaced with the Artificial neural network(ANN) which works based on the training and testing process. This network is trained by back propagation training algorithm. The back propagation algorithm is one of the most famous algorithms to train a feed forward network. The proposed technique will be implemented in MATLAB platform and the output performances will be evaluated .Finally, the 
INTERNATIONAL JOURNAL OF INNOVATIVE RESEARCH IN ELECTRICAL, ELECTRONICS, INSTRUMENTATION AND CONTROL ENGINEERING Vol. 3, Issue 12, December 2015

evaluated performances of the proposed control scheme Once the neural network training process is completed, the will be compared with the conventional control scheme.

\section{BACK PROPAGATION LEARNING ALGORITHM STEPS}

Step 1: Initialization of the input layer, hidden layer and output layer weights of the neural network, i.e., change in motor torque ${ }_{\Delta T}$, change in flux $\Delta \phi$ and residual $r(k)$.

Step 2: Learning the network according to the input and the corresponding target.

Step 3: Calculate the back propagation error of the target $r_{1}, r_{2}$ and $r_{k}$.

$\left.\begin{array}{l}B P_{\text {error }}^{1}=r_{1}^{N N(\text { tar })}-r_{1}^{N N(\text { out })} \\ B P_{\text {error }}^{2}=r_{2}^{N N(\text { tar })}-r_{2}^{N N(\text { out })} \\ B P_{\text {error }}^{k}=r_{k}^{N N(\text { tar })}-r_{k}^{N N(\text { out })}\end{array}\right\}$

Where, $r_{k}^{N N(t a r)}$ is the network target of the $k^{\text {th }}$ node and $r_{k}^{N N \text { (out ) }}$ is the current output of the network.

Step 4: The current output of the network is determined as follows,

$$
\left.\begin{array}{l}
r_{1}^{N N \text { (out ) }}=\alpha_{1}+\sum_{n=1}^{N} w_{2 i 1} r_{1}^{N N}(n) \\
r_{2}^{N N(\text { out })}=\alpha_{2}+\sum_{n=1}^{N} w_{2 i 2} r_{2}^{N N}(n) \\
r_{k}^{N N \text { (out })}=\alpha_{k}+\sum_{n=1}^{N} w_{k n k} r_{k}^{N N}(n)
\end{array}\right\}
$$

Where, $\alpha_{1}, \alpha_{2}$ and $\alpha_{k}$ are the bias function of the node 1,2 and $k$ respectively.

$$
\left.\begin{array}{l}
r_{1}^{N N}(n)=\frac{1}{1+\exp \left(-w_{1 n 1} r_{1}-w_{2 n 1} r_{2}\right)} \\
r_{2}^{N N}(n)=\frac{1}{1+\exp \left(-w_{2 n 2} r_{2}-w_{k n 2} r_{k}\right)} \\
r_{k}^{N N}(n)=\frac{1}{1+\exp \left(-w_{k n k} r_{k}-w_{1 n k} r_{1}\right)}
\end{array}\right\}
$$

Step 5: The new weights of the each neurons of the network are updated by $w_{\text {new }}=w_{\text {old }}+\Delta w$. Here, $w_{\text {new }}$ is the new weight, $w_{\text {old }}$ is the previous weight and $\Delta w$ is the change of weight of each output. The change of weight is determined as follows:

$$
\left.\begin{array}{l}
\Delta w_{1}=\delta \cdot r_{1} \cdot B P_{\text {error }}^{1} \\
\Delta w_{2}=\delta \cdot r_{2} \cdot B P_{\text {error }}^{2} \\
\Delta w_{k}=\delta \cdot r_{k} \cdot B P_{\text {error }}^{k}
\end{array}\right\}
$$

Where, $\delta$ is the learning rate $(0.2$ to 0.5$)$.

Step 6: Repeat the above steps till the ${ }_{B P_{\text {error }}}$ gets $\operatorname{minimized~}_{B P_{\text {error }}<0.1}$ network is trained well for the identifying $r(k)$ of the input.

Based on the output of the network, the control pulses of the 5-level inverter have been decided by using the SVM technique.
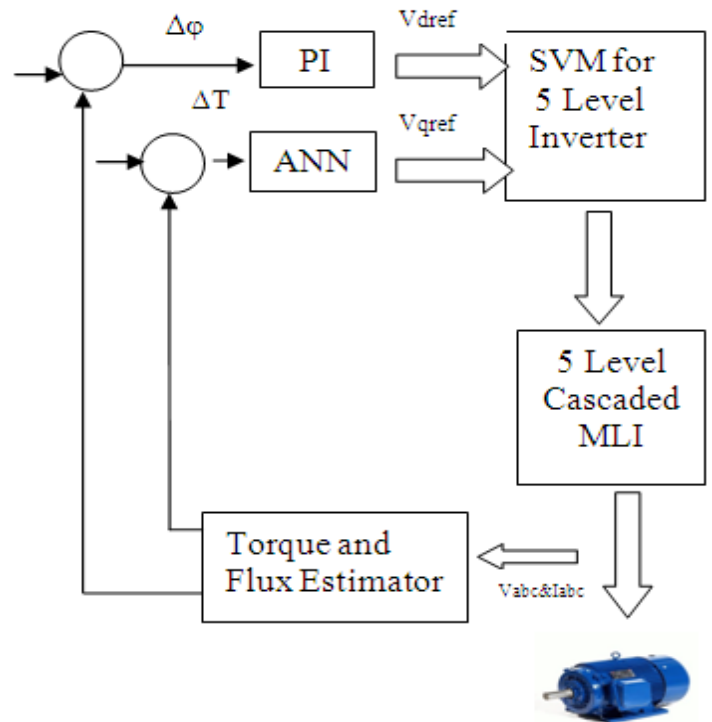

Fig.1. Structure of Proposed Control Technique

\section{RESULTS AND DISCUSSIONS}

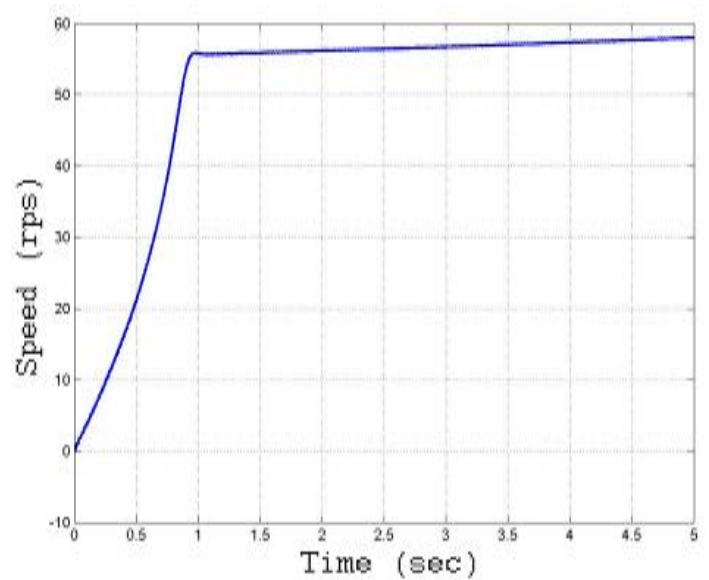

Fig.2 Induction Motor Speed for proposed method

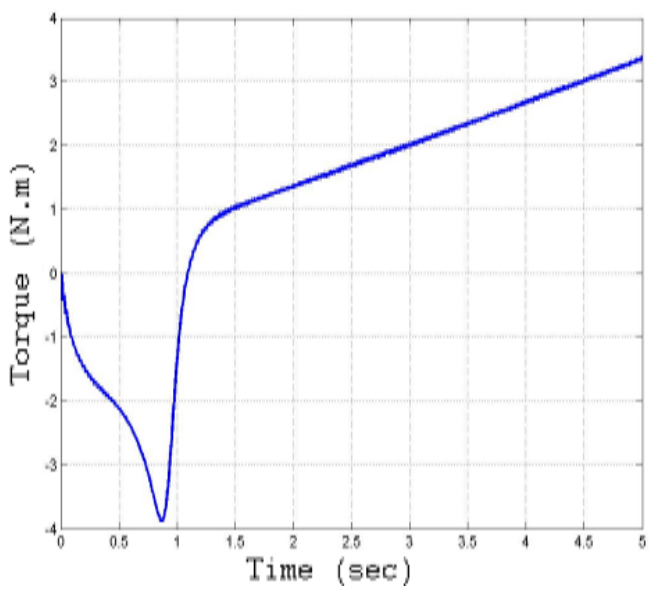

Fig.3 Induction motor Torque for proposed 
INTERNATIONAL JOURNAL OF INNOVATIVE RESEARCH IN ELECTRICAL, ELECTRONICS, INSTRUMENTATION AND CONTROL ENGINEERING Vol. 3, Issue 12, December 2015

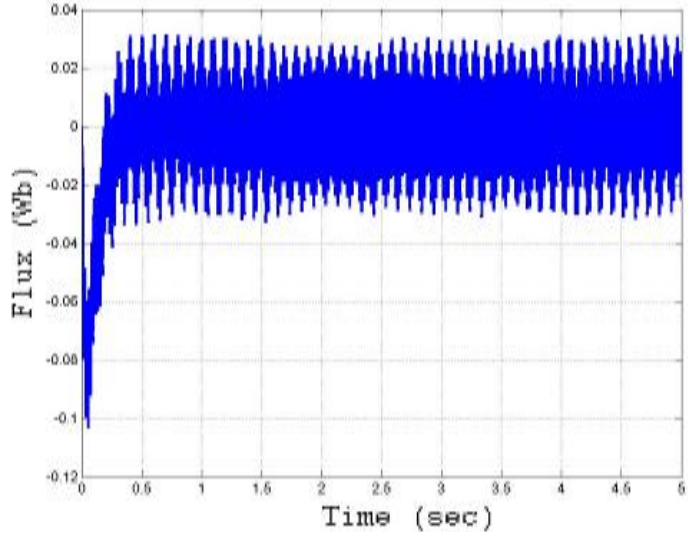

Fig.4 Induction motor Stator Flux Distortion

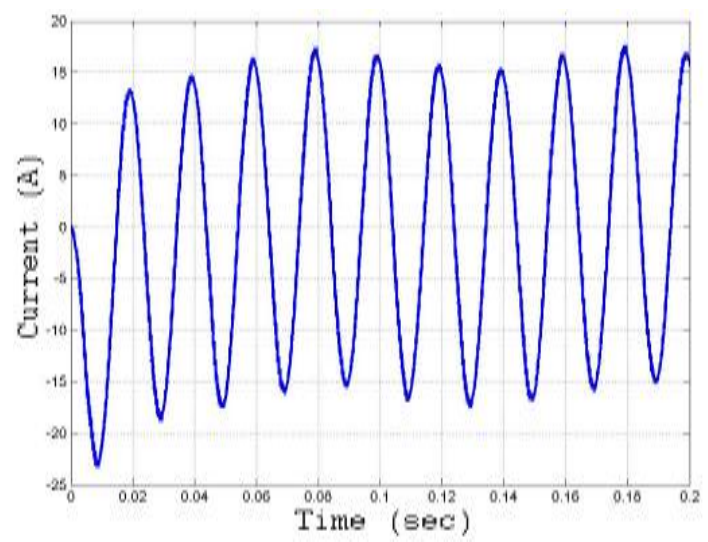

Fig 5: Induction motor stator current

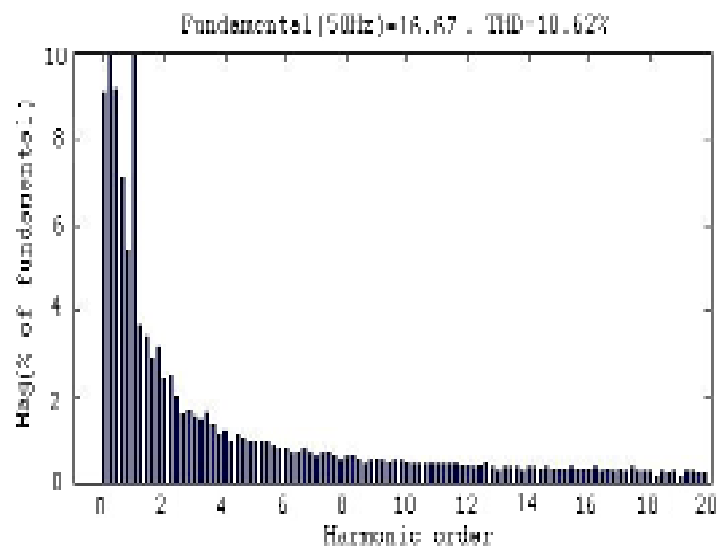

Fig.6 Harmonic Analysis for DTC with PI Controller

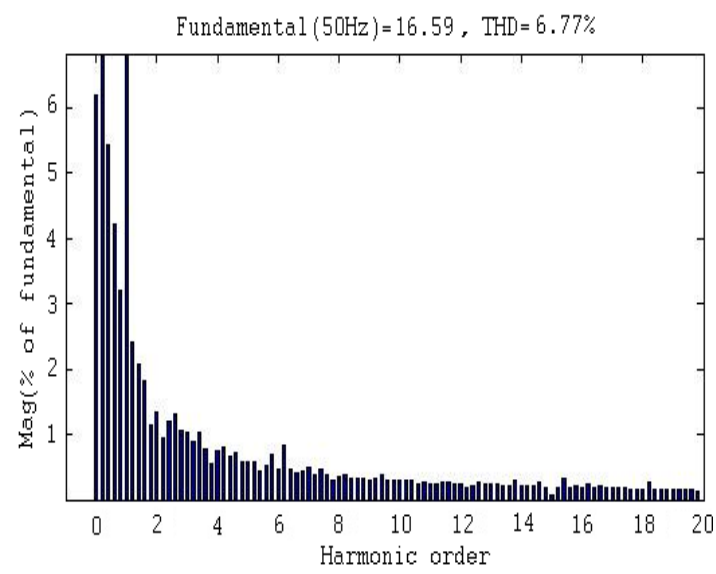

Fig.7 Harmonic Analysis for DTC with Proposed
V. COMPARATIVE ANALYSIS

\begin{tabular}{|l|l|l|}
\hline & $\begin{array}{l}\text { DTC with } \\
\text { Normal PI } \\
\text { Controller }\end{array}$ & $\begin{array}{l}\text { DTC with } \\
\text { Proposed } \\
\text { Technique }\end{array}$ \\
\hline THD & $10.62 \%$ & $6.77 \%$ \\
\hline Fundamental Voltage & $16.67 \mathrm{~V}$ & $16.59 \mathrm{~V}$ \\
\hline Stator Flux Distortion & +0.037 to - & +0.03 to - \\
& $0.037 \mathrm{~Wb}$ & $0.03 \mathrm{~Wb}$ \\
\hline
\end{tabular}

\section{CONCLUSION}

This paper explains an Intelligence Direct Torque Control (DTC) of induction motor using 5-level cascaded inverter with space vector modulation. Here the ANN is utilized for the DTC of the induction motor. The reference quadrature axis and direct axis voltage is assumed as the target of the ANN with the corresponding input parameters like the change in torque and change in flux. Depending on these dataset, the ANN has been trained using the back propagation algorithm. Then the proposed system performance been validated through simulations. The effectiveness of the proposed method has been analyzed by conventional method. From the results analysis, we could justify that the proposed intelligence technique has an improved dynamic performance, smaller motor torque, reduced flux ripple and lower THD, which is competent over the other techniques.

\section{REFERENCES}

[1] Anjana Manuel and Jebin Francis, "Simulation of Direct Torque Controlled Induction Motor Drive by using Space Vector Pulse Width Modulation for Torque Ripple Reduction", International Journal of Advanced Research in Electrical, Electronics and Instrumentation Engineering, Vol. 2, No.9, pp.4471-4478, 2013

[2] Srujana Dabbeti and K. Vara Lakshmi, "Sensorless Speed Control of an Induction Motor Drive using Predictive Current and Torque Controllers", Advance in Electronic and Electric Engineering, Vol.3, No.9, pp.1177-1196, 2013

[3] Bambang Purwahyudi, Heri Suryoatmojo, Soebagio, Mochamad Ashari and Takhashi Hiyama, "Feed-Forward Neural Network for Direct Torque Control of Induction Motor", International Journal of Innovative Computing, Information and Control, Vol.7, No.11, pp.6135-6145, 2011

[4] Narender Kumar and Joginder Singh, "Direct torque control of three phase induction motor using matlab", International Journal of research in applied science and engineering technology, Vol.1, No.2, pp.16-22, 2013

[5] Petar R. Matic, Branko D. Blanusa and Slobodan N. Vukosavic, "A Novel Direct Torque and Flux Control Algorithm for the Induction Motor Drive", In proceedings of IEEE conference on electric machines and drives,Vol.2, pp.965-970, 2003.

[6] Xin Wei, Dayue Chen and Chunyu Zhao, "Minimization of torque ripple of direct-torque controlled induction machines by improved discrete space vector modulation", Journal of Electric Power Systems Research, Vol.72, No.2, pp.103-112, 2004

[7] Cheng-Yi Chen, "Sliding Mode Controller Design of Induction Motor Based on Space-Vector Pulse width Modulation Method", International Journal of Innovative Computing, Information and Control, Vol.5, No.10(B), 2009

[8] A. Abbou and H. Mahmoudi, "Performance of a Sensor less Speed Control for Induction Motor Using DTFC strategy and Intelligent Techniques", Journal of Electrical Systems, Vol.5, No.3, pp.64-81, 2009

[9] Eman El-Gendy, Abdelhameed F. Ibrahim, Sabry F. Saraya and Fayez. F. G. Areed, “A Sliding Mode Controller for a Three Phase Induction Motor", International Journal of Computer Applications, Vol.64, No.11, pp.33-39, 2013

[10] Yongchang Zhang, Jianguo Zhu, Zhengming Zhao, Wei Xu and David G. Dorrell, "An Improved Direct Torque Control for ThreeLevel Inverter-Fed Induction Motor Sensorless Drive", IEEE Transactions on Power Electronics, Vol.27, No.3, 2012

[11] M. Nasir Uddin and Muhammad Hafeez, "FLC-Based DTC Scheme to Improve the Dynamic Performance of an IM Drive", IEEE Transactions on Industry Applications, Vol.48, No.2, pp.823-821, 2012 